\section{Who to turn to when it's time to sell}

Selling a dental practice can appear to be one of the most stressful decisions of your career - but that doesn't need to be the case.

With the assistance of the expert, award-winning team at practices4dentists, selling your practice can be a stress-free, seamless experience.

Each member of the team is an expert in the field, and can help you evaluate your property, organise any paperwork, help you prepare your staff and more. In fact, they can aid you every step of the journey, meaning that you can rely on their support throughout.

So, what are you waiting for? If you are looking to sell your practice, contact the team at practices4dentists today.

For more information call 08453455060 or 0754 DENTIST.

Email info@4dentistsgroup.com or visit www.4dentistsgroup.com.

\section{One shop - same great service}

All of your favourite Optident products are now available through Henry Schein Dental, giving customers of both brands a faster and more streamlined buying experience.

Optident has been part of the Henry Schein Group since 2013, but only now has its full fantastic range of products become available online at www.henryschein.co.uk. This new breakthrough gives Henry Schein's thousands of customers access to an even wider range of goods and materials, all available through their existing Henry Schein account.

The move broadens the range of products on which Rewards points can be claimed and means there will be more special offers, frequent vendor days and additional money-saving deals from leading suppliers, providing even more support to dental practices. The change will also help streamline internal accounts payable processes, with only one invoice to administer and one bill to pay, saving time and money.

Take a look at Optident at Henry Schein Dental www.henryschein. co.uk and start streamlining your purchasing processes. If you require more information, contact your local field consultant who will be happy and able to help. www.henryschein.co.uk

\section{Seamless integration of intraoral scanner}

Align Technology, Inc. has announced a new function which enables the seamless integration of the iTero intraoral scanner with Systems for Dentists (SfD), a practice management software system from the third-largest dental software company in the UK. SfD's software system facilitates the management of appointment booking, medical history records, patient details, clinical notes, periodontal charting and allows for integration with third-party software.

Following the integration with SfD, iTero scanner operators will be able to create scanned patient records using the software by having one source of data entry. iTero users will also benefit from improved connectivity and the facility for automated upload of intraoral images to improve traceability and reduce human error. iTero scanner operators will also be able to directly access MyiTero.com via SfD, without separate logins and with a greater degree of speed and efficiency.

Systems for Dentists offers test conversions free of charge and arranges training to facilitate the migration to the system for iTero intraoral scanner users.

More information is also available from www.itero.com.

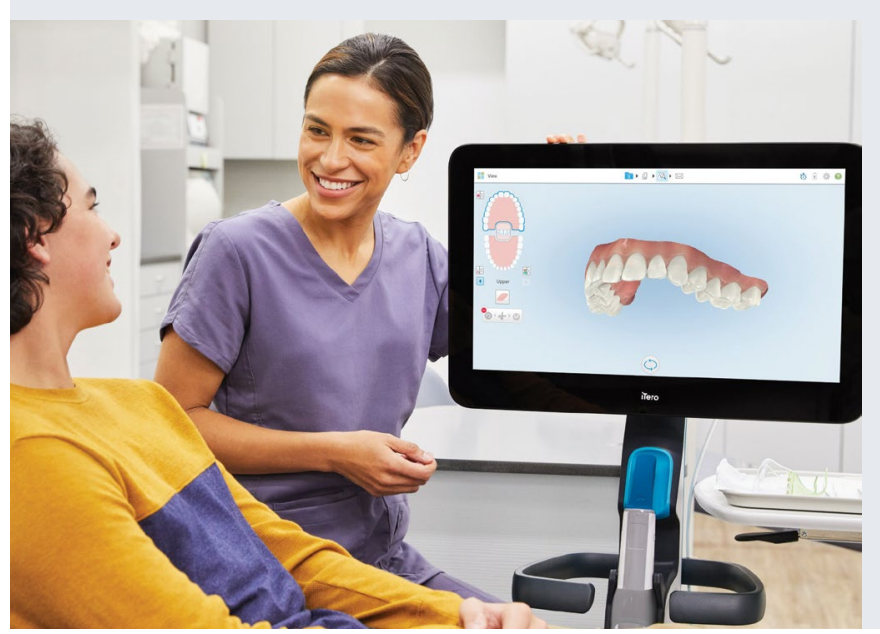

\title{
New sustainable interdental brushes unveiled
}

$\mathrm{TePe}$ is committed to the details that make all the difference... so as part of its commitment to achieving carbon neutral products and packaging in 2022, it has launched a more sustainable Interdental Brush (IDB).

Manufactured in Sweden using 100\% green energy, TePe's new Interdental Brush is the next step in helping the dental industry to be more environmentally friendly.

In addition to being made with $100 \%$ green energy, the new TePe IDBs come in $100 \%$ recyclable packaging, made from plant-based renewable sources.

TePe maintains the high quality that professionals have come to expect from its products.

On its journey towards carbon neutrality, TePe has reduced its interdental brushes' carbon footprint by $80 \%$. This has been achieved by using the existing plastic manufacturing infrastructure

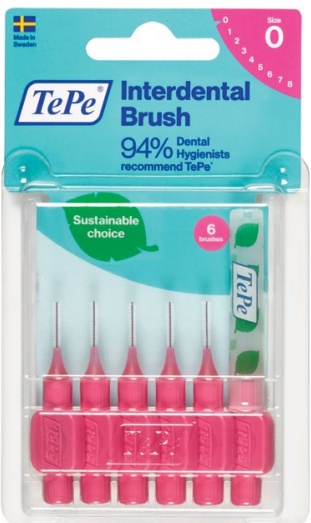

but with more sustainable raw materials. Pine oil is a by-product of the paper industry which is mixed with oils from other sources - a process called the Mass Balance Method, which has been independently audited by the ISCC.

$\mathrm{TePe}$ is committed to having a sustainable impact on the professional dental sector. TePe's efforts go beyond its own product range as it looks to educate and support consumers on making more planet conscious choices, through top tips and advice and working with third party sustainability experts.

The more sustainable interdental brushes from TePe are now on sale from your dental wholesaler; the new soft bag contains eight IDBs and now with easy opening.

For more details on TePe's sustainable products and initiatives, visit www.tepe.com or speak to your local practice relationship manager. 